Meta

Journal des traducteurs

Translators' Journal

\title{
Japanese Interpreters in their Socio-Cultural Context
}

\section{Masaomi Kondo}

Volume 33, numéro 1, mars 1988

Traduction et interprétation au Japon

Translation and Interpretation in Japan

URI : https://id.erudit.org/iderudit/003336ar

DOI : https://doi.org/10.7202/003336ar

Aller au sommaire du numéro

Éditeur(s)

Les Presses de l'Université de Montréal

ISSN

0026-0452 (imprimé)

1492-1421 (numérique)

Découvrir la revue

Citer cet article

Kondo, M. (1988). Japanese Interpreters in their Socio-Cultural Context. Meta, 33(1), 70-78. https://doi.org/10.7202/003336ar d'utilisation que vous pouvez consulter en ligne.

https://apropos.erudit.org/fr/usagers/politique-dutilisation/ 


\section{JAPANESE INTERPRETERS IN THEIR SOCIO-CULTURAL CONTEXT}

MASAOMI KONDO

Daito Bunka University, Tokyo

This paper is an attempt to place Japanese interpreters in the socio-cultural context of Japan, so that some peculiar features of their life and profession can be better understood. In particular, the relatively low social status we endure in Japan, both in comparison with members of other professions in the same country and with members of the same profession in other countries, seems to be explained most adequately in the socio-cultural context of the country in which we practice our profession, for the Japanese culture seems strongly prejudiced against oral aspects of the people's language life. Moreover, there is a feature of the Japanese language which seems to reinforce this societal tendency.

\section{STATEMENT OF THE PROBLEM}

Is the social status of Japanese interpreters really low ? A few episodes should suffice to make the point. It was a minor shock to me to hear a free-lancing Swiss colleague of mine state that his bank was willing to lend him any amount of money! He had just built a very nice house on a plot exceeding 1000 square meters on the outskirts of Geneva, naturally by borrowing most of the money from the bank. He was being urged by the same bank to borrow even more to buy a new and more expensive car, a yacht, and what not, which he was resisting to the consternation of the bank officials.

He may well be an exception even among Geneva-based interpreters, probably themselves exceptions in the overall community of internreters in the world. The bank might have been on a lending spree. But in Japan no bank would provide a major loan to a free-lance interpreter on the basis of his profession, even when he was actually earning an adequate income. Many colleagues of mine here have had to rely on their agencies to convince banks of their credit-worthiness when purchasing not a mansion but merely a flat. (Here is one way sympathetic agencies can help interpreters in Japan.) Members of other professions in Japan, such as doctors, lawyers, accountants, etc., seem to suffer from no such constraints. And aren't bankers guardians of common sense in our society?

Let me mention a case that is perhaps a little extreme but nonetheless very real and somewhat humorous. A technician friend of mine was quite excited when I quoted a Japanese newspaper article which, after describing a Hawaian-Japanese conference, closed by saying in the most nonchalant way that "the conference was conducted with the use of simultaneous interpreting equipment". No mention was made of the interpreters as human beings nor of the interpreting service provided with the equipment, but only of "the use of interpreting equipment" (of course, there ares no technicians involved, either). After this experience I have become somewhat over-sensitive about the way in which things and people are referred to. Thus, I had to sympathize deeply with an electrone (an electronic music instrument) player when, at the dress rehearsal of a ceremony, the stage manager said, "At this juncture the electrone will start playing this tune". Not the player but the instrument plays! Possibly the point is lost in English be- 
cause inanimate entities can be used as the subject of a factive verb, denoting intentional acts, but in Japanese that construction is rare and gives a distinct impression of avoiding mentioning people.

I have always assumed that translators are our colleagues, partly because I myself do both interpreting and translating but mostly because of a more fundamental reason : both translators and interpreters are essentially engaged in the same cross-cultural communication, different only in form. Thus, I felt terribly betrayed when I saw an established translator, speaking to aspiring translators, refer to interpreters as follows : "You (as a translator) don't have to speak English well. (But) unless your words contain social philosophy, you are a flunk as an internationalist. Suppose you are asked, 'What is freedom ?' or 'What is democracy ?' Unless you can respond by throwing out ten or twenty definitions, skits or jokes, you won't even count. If a poor speaker and poor 'hearer' (meaning a translator - Kondo) can excell simultaneous interpreters, it is on the strength of philosophy that (the translator thus possesses) ${ }^{1}$." Translators must be social philosophers, while interpreters are considered mere hearing and speaking machines with neither mind nor intelligence.

If some accuse me of being a little masochistic or a bit self-pitying, they may be partially right. But at the same time they should at least see why I feel this is the way we interpreters are looked upon by many people in this country (perceptive readers could perhaps guess that there have been a number of such incidents that $I$ refuse to remember). Naturally there are also many Japanese who look upon us in a more favorable light. We encounter a good number of understanding clients. Nor do things stand still (see below). But there definitely seem to be enough signs indicating a generally unfavorable perception of the interpreting profession in Japan to justify a search for the factors behind it.

Why then is the interpreters' status in Japan so low economically, socially, culturally and even intellectually?

First of all, maybe we ourselves are to blame. Maybe we are not doing a good job in the booth or at the conference table. Maybe our behavior invites scorn or we offend people. Maybe we act "cheap".

Suppose for a moment that it was established that we Japanese interpreters are substantially to blame for our low status. Even then, a relevant question would be : Why do more talented people not enter the profession and stay there? As a matter of fact, a number of experienced interpreters have left the profession for other jobs which must be more rewarding in their eyes, such as teaching, managing a firm, becoming TV newscasters, etc. (I myself teach, although I remain a practising conference interpreter.) To me this is not at all a chicken-and-egg question.

In fact, it has much to do with the speaking aspect of our language life in Japan. And in order to understand this point at all, we must look at the Japanese culture more closely. The term "culture" is used here in the broad socio-anthropological sense, meaning all that is learned by man after his birth in the process of socialization, i.e., language, fine arts, customs and mores, beliefs, ways of communication, ways of life and all the other products of a group of people, handed down from generation to generation.

\section{THE HIGH-CONTEXT CULTURE OF JAPAN}

Cultural and ethnic homogeneity of Japan are often mentioned as a peculiarity of Japan, although, strictly speaking, that is not the case. There has always been a minority of the Ainus with their own culture, including language. There are about a million Koreans and some Chinese residents in Japan (some naturalized), most of whom were forcibly brought to Japan during the days of Imperial Japan or are descendants of these victims. (And there is a Japanese minority who are still discriminated 
against due to their forebearers low status during the Tokugawa feudal era.) And yet there pervades the notion of ethnic and cultural homogeneity among the overwhelming majority of the Japanese, and the concomitant antipathy toward the non-Japanese (and anybody who "does not belong" to the in-group), which has caused indescribable human and psychological as well as social and economic suffering to the members of these minorities in Japan. As will be shown below, interpreters in Japan are also victims of this unwarranted Japan-centeredness.

How has this homogeneity-myth been created then? Perhaps there are some historical factors in operation here ${ }^{2}$. The long history of Japan has seen virtually no largescale immigration of people after the present stock was fairly well established. Even the Chinese and Korean influences in religion and writing were successfully integrated into the people's religious life and the Japanese language for ten centuries. Japan's geography helped in maintaining isolation, certainly during the days of meager transportation but even today to a considerable extent.

The country was deliberately closed for 270 years before it was forced open in the late 19th century. Some historians tell us that the small window opened for trading with only the Dutch and the Chinese brought in more knowledge about the world than many have surmised. And yet that knowledge was deliberately kept among a very small group of officials. The result was the growing uniformity in the life style of the people, in their perception of social relations, in esthetic sense, i.e., in the culture. Japan as a culture came to embrace less and less foreign elements, resulting in a high level of cultural homogeneity.

Naturally things started to change once modernization became the national slogan. But many aspects of the Japanese culture refused changes, especially in the atmosphere of valuing both "the Japanese spirit and Western learning". While the science and technology of the West had to be learned to avoid the fate of many Asian peoples, the Japanese spirit was still upheld as valid. Much of the traditional village community mentality also remained, clearly distinguishing insiders from outsiders. Many strands of social thinking were "imported", but the extent to which they made a real dent on the social psychology of the Japanese is still a matter of debate.

Of particular interest to the linguistically oriented is a forceful hypothesis put forward by Akira Yanabu. He points out that all the important concepts in the imported Western social thinking, such as democracy, liberty, society, etc., were rendered into Japanese by words of Chinese origin or by coining new words made up of Chinese characters, which were instantly recognizable as translations of the "imported" concepts (because they invariably had two or four Chinese characters combined). This, according to Yanabu, prevented genuine interaction (indeed communication) between the traditional Japanese mentality and the Western perceptions of human relations among themselves, with society and with nature, while such interaction was essential for the Japanese culture to really change or generate a valid synthesis. While Western science and technology was rapidly absorbed, there was little profound soul-searching on the part of many Japanese, but merely a superficial acceptance of Western thinking, which can be (and is) easily discarded. Excessive syntactical distortion of Japanese due to thoughtless and perfunctory imposition of original language structures on the target language essentially produced the same effect ${ }^{3}$. - This hypothesis raises many interesting questions. Although it can easily be carried too far, I feel that it points to an important linguistic factor to be taken into account in the study of modern Japan.

This cultural homogeneity characteristic of an overwhelming majority of the Japanese plays an important part in determining the way they communicate. When a group of people behave and think in essentially the same way, there is less need to explain one- 
self explicitly. There is less need for overt communication among them. The smallest cues and fewest words start to suffice.

What then? Then people come to scorn those who fail to understand subtle communication. You must be able to "understand ten by hearing only one", as the saying goes. If not, you don't belong to the group. If one superimposes the controls exercised by the traditional village community (Gemeinde) on its members, one gets a rather fornoidable barrier to the rise of meaningful inner dissent.

But what then? Then people come to scorn those who use a lot of words to communicate. I deally two persons facing each other should just sit silently, perhaps sipping green tea, while all the necessary messages flow back and forth. If you can do this, you have mastered the art of acting on the strength of your personality and of silent communication, even without recourse to gestures and other normal forms of silentlanguage in the sense used by Edward Hall in his ground-breaking book on non-verbal communication.

Of course, this talk about perfect telepathic communication is going a bit too far. But Edward Hall offers another useful concept in understanding this specific feature of the Japanese culture. He proposes classifying various cultures as high-context or lowcontext. In high-context cultures the context is important, i.e., the context in which actual spoken words are placed goes a long way towards illuminating the meaning of those words, so that one needs to rely less on the words actually uttered to convey a message. In low-context cultures you need more words to communicate, because utterances stand relatively alone with little help from the context in which they are made 4 . In light of these definitions, one can easily agree with Hall that Japan is a typically high-context culture.

Some Japanese linguists characterize the Japanese culture as taciturn in contrast to talkative English-language cultures ${ }^{5}$. They maintain that to call someone a person of few words in Japan is an expression of admiration for the nobleness of his character, not just a description of what kind of a person he or she is. Neither is it merely praise for his or her skills in the strategic use of words and silence, which is precisely what the English proverb "Silence is golden" promotes. On the other hand, garrulity is frowned upon as vulgar in Japan.

An example cited by these authors should also be of interest to us. One of the ways the Japanese themselves have traditionally referred favorably to their country - as the country of the rising sun - was to call it a country where no kotoage took place : kotoage literally and originally meant "to give verbal expression", although now it has the slight negative connotation of "raising an issue to cause commotion". The implication is that the Japanese have thought of verbal expression as something that should not take place. (One could alternatively interpret this reference as the admonishment of the ruling class of the time to its subjects not to raise voices against the establishment. This would mean that this servile attitude toward power has survived all the turmoils of modern Japanese history.)

These authors also maintain that the perception of words as having some miraculous spiritual power is not confined to Japan at all, but that this belief made the Japanese tongue-tied, while the same belief led English-speaking peoples in the opposite direction, to the active use of words to influence events.

This cultural trait now definitely conditiond the Japanese people to value silence profoundly - if not outright silence, at least a hesitant manner of speaking which is considered preferable to eloquent outpouring of words. It was none other than the Nobel Laureate Yasunari Kawabata himself who said, "In Japan eloquence has never been a necessary condition for a man to be great as it is in many other lands. No one has made 
a dent on the history of Japan by eloquence. Instead, orators have been held in contempt as "rogues of the tongue'6." I think it was Haruhiko Kindaichi, one of the best known linguists in Japan and one of the pioneers in the study of spoken Japanese skills since early post-war days, who once said that one did better among the Japanese if one spoke falteringly, in a hesitant and mumbling tone of voice. A smooth flow of words would give an impression of superficiality and insincerity. Imagine! This is the advice of a master linguist, who was a popular speaker himself.

I have actually met many Japanese in person (and seen others on TV) who are reputed for their influence and intellectual prowess and who, indeed, follow the advice of Kindaichi, many of them no doubt unwittingly. They may write beautifully but, when they speak, words come out haltingly, many sentences remain open-ended, new ideas are inserted liberally, digressions occur without restraints, rarely referring to the subject matter specifically. Sometimes they even close a whole presentation by employing a standard phrase which I sometimes feel compelled to interpret as : "I apologize for having spoken indeed quite incoherently". (Readers should realize that I must fight hard to resist an urge to emphasize "incoherently" by supplementing it with "incongruously", "illogically", "in the most haphazard manner", "with no sequence", etc.) Unless I make this point very, very clear, the audience would think that interpreters were doing a lousy job of it. This kind of experience, however, humbles me and restrains me from making bold statements such as : "The interpreter's job is to bridge the gap between cultures". I do not know how to do it.

Professor Shunsuke Tsurumi is among the better known philosophers in Japan, an accepted member of the intellectual community in the country. He is somewhat unique in having been educated in the United States of America prior to the Pacific War, for about four years in his late teens. And yet he reveals his "conviction, statistically provable if not logically, that those Japanese who can converse in English are not to be trusted" ${ }^{\text {}}$. Unfortunately the context in which this point is made gives little clue as to what he means exactly. Nor are the reasons for his statement specified. The fact that English was the language of the post-war occupation forces may have something to do with it. Maybe he was merely trying to be as humble he says he was, speaking to a group of Canadians in English. At any rate, I sense that his feelings of mistrust toward those Japanese with English-speaking skills are genuine.

Professor Tsurumi is not alone in expressing misgivings toward English-speaking Japanese. I have had a number of acquaintances telling me of their deep-rooted belief that those Japanese who speak English must be incompetent idiots. One reason given that I remember well is that they must have spent too much time practising speaking English, leaving too little time to study anything else or to do any thinking. To many Japanese intellectuals true to the dictates of their culture, the practice of spoken English must look like a rather silly and grossly inferior kind of exercise.

I have a Japanese friend who met an American girl while touring Southeast Asia and later married her. He recently visited the United States for the first time in his life but came back hating the country of his wife's origin, because he is a man of few words. He would quietly sip his sake-wine and mostly listen to others talk. In Japan he is well liked and highly respected. But across the Pacific you have a culture which would automatically associate silence with absence of intellect. There people assume that, if you keep quiet, you have nothing to contribute, nothing of substance to say. Thus, you tend to be ignored and slighted. Nobody likes that. Even when you realize the cause of your unhappiness, you cannot change your behavior overnight.

Now, what you can do to get a feel of how a Japanese interpreter is viewed in the Japanese culture is to reverse the case of my friend mentioned above. Put a verbally ag- 
gressive non-Japanese in the high-context and taciturn Japanese culture and imagine how he or she might be viewed. Furthermore, a professional interpreter does as his profession, what the culture commands not to do. There is an inherent dilemma in being an interpreter in Japan. In order to be useful to society, an interpreter must do what society forbids him to do. In a rather fundamental sense he is an outcast.

\section{ADDITIONAL FACTORS AND CONCLUDING REMARKS}

Whatever follows such a radical statement must seem like an anticlimax. But the picture remains incomplete unless some mention is made of a feature of the Japanese language which seems to reinforce the very tendency I have described above : deemphasis on speech. The extent to which language influences behavior, thought, values, etc. of speakers, i.e., their culture, is still being debated. But at least in the following sense the Japanese language seems to offer particularly strong support to Japan's cultural antipathy toward the speaking aspects of the people's language life.

It is not easy to talk of Japanese because it is my native tongue, but this cultural trait seems to have a lot to do with our use of Chinese characters as an integral part of Japanese. First of all, they are ideograms, each character representing a meaning, while the alphabet is a phonetic system. With ideographs you can jot down a message without the medium of sound, often even without knowing how the ideogram you are using is to be pronounced. In the same way you can understand written ideograms without knowing how they are pronounced, with no intermediary of sound, and this occurs quite often. Often new words are coined by combining two or four Chinese ideograms, without the coiner first thinking about how they should be pronounced. In the beginning the ideogram is identified not by how it is pronounced but by how it is written. You could almost say that people can pronounce the neologisms any way they like, because once they look at the ideograms the meaning becomes instantly apparent in most cases.

The other side of the same coin is the presence of a notoriously large number of homonyms in Japanese. A medium-sized handy Japanese dictionary on my desk lists 25 different words with the same pronunciation of kikoh, as well as 19 kikan's, 13 kishi's, 19 kisel's, 18 kyushi's, etc. (It took me only about five minutes to make up this list by going over 90 pages out of the total 2100 pages of the dictionary.) And few of them are eliminated through homonymic clashes, because once you see them written down it is easy to distinguish them.

Pronunciation occupies only a secondary place in these cases. Of primary importance is what you see written down. Language then tends to be equated with the written language. Speech becomes not only ephemeral but also superfluous. Thus, the use of Chinese ideograms in Japanese (or, for that matter, in Chinese also) definitely seems to reinforce an important feature of the Japanese culture, important at least to those engaged in the use of spoken language.

I have two additional points to make regarding the place of the spoken language and that of the interpreting profession in Japan. One is about the lack of education in the speaking skills. It is not at all difficult to believe, in light of all the points I have made so far, that speech education occupies hardly any place in the total language education provided in the country. This applies especially to the teaching of Japanese, but also to the way other languages are taught. At any rate, there is hardly any training given in speaking skills anywhere in the school system, from primary schools all the way through universities, a clear contrast to the many compulsory speech courses in American colleges and universities. Thus, the conspicuous lack of education in speaking skills in Japan becomes an important component in the mutually reinforcing sequence of factors that undermine the place of the spoken language in the Japanese culture ${ }^{8}$. 
I must shift the focus of attention somewhat to make my only remaining point about the social position of interpreters in Japan. There is an institutional factor in operation in Japanese society which also tends to hinder improvement of the interpreters' working environment in Japan. In many parts of the world workers tend to identify themselves in the labor market by the skills or the jobs they have acquired. If you have learned the skills required to become a welder, you are a welder, no matter where you work. You get paid as a welder at welders' rates. You may belong to the welders' association or the trade union representing welders, and in many countries there is a history of guilds for different skills. But it is not so in Japan.

It is well known that in Japan workers are identified by the company they work for. Indeed your very person is identified that way. When you introduce yourself, you give the name of the company which employs you even before you give your own name. You are not a welder first. First you are a member of the group that forms the company, and you just happen to be put in charge of welding at a particular point in time. You will work for the same company, but your job may change as the company evolves prompting you to learn new skills. Japan has a different way of organizing the labor market.

Putting aside the on-going debate as to which method of labor organization is better adapted to the rapid technological innovation and changing industrial structure that are the order of the day in the world now, let us concentrate on how a free-lance interpreter fares in Japanese society. Well, he or she has a skill, but is not employed by a particular company. As a free-lance interpreter you have exactly what you should not have, and do not have what you should have if you want to acquire an established place for yourself in the Japanese economy and society. As a free-lance you fall outside the normal framework of Japanese working life. Government ministries categorically refuse to accept the bill for interpreting services rendered if it is issued in the name of a person; it must come from an incorporated entity. Here is another practical reason why sympathetic agencies can help us or why we ourselves must form an incorporated body. It is possible to free-lance in Japan, as many of us do, but there are more difficulties than can perhaps be imagined in many other parts of the world.

I have painted a rather gloomy picture of the status of Japanese interpreters in the country. But are we really doomed? Is there no way out of this deadlock ?

There are various signs of improvement already. Many of us enjoy good working relations with many of our clients, who understand the value of our work far better than they used to. They also understand the various difficulties we face and the needs that must be met if we care to effectively carry out our task. The process of improvement will be slow, but, after, all there will always be some nasty clients and impossible speakers anyway.

Without applying the extremes of Madison Avenue techniques, there are a number of things we can do to improve our social standing in Japan. We must do a good job in a dignified manner, as best we can under specific circumstances. There should be some practical and effective arrangement to improve our own skills. There is a definite need for more research both theoretical and applied, about the nature of our job as well as methods of improving our skills. We could benefit a lot from the research effort in the West both on interpreting in general and that involving Japanese specifically ${ }^{9}$. Many of us should try to acquire a third language. Maybe we should better explain our profession to the public at large in terms of the nature of the work we do, the difficulties we face, various achievements we should be rightly proud of, etc.

And there is a wind of change on the cultural scene, too ${ }^{10}$. A growing number of people are showing intense interest in learning how to speak. Recently, a popular newspaper column mentioned this trend specifically ${ }^{11}$. The columnist asked how many 
books have been recently published on various aspects of speaking skills. The computer print-out listed as many as 323 titles, while there were only 38 titles on how to write (there was no mention of how well they are selling). Private speech schools in Tokyo are reportedly prospering. A friend of mine teaching in the Department of Pedagogy which trains prospective teachers of Japanese for primary and junior high schools in Japan is emphatic about the urgent need to introduce speech and oral communication classes in the school curriculum.

However, the use of Chinese ideograms with the resultant impact on the nature of Japanese will not cease, unless the whole Japanese language goes through some dramatic changes by adopting some of the bizarre proposals put forth by different people. They include persons like Ryunosuke Akutagawa, one of the best known novelists in the Meiji Japan, who proposed the adoption of the alphabet as the writing system; Arinori Mori, the first Minister of Education in the Meiji government, who seriously contemplated the adoption of English as Japan's national language ; and Naoya Shiga, a reputed novelist often referred to as the "God of Novels", who early in the post-war days proposed the replacement of Japanese by French. But it is difficult to imagine anybody being serious about such proposals now.

If, however, the de-emphasis on speech was based on an overall lack of need to spell things out in detail due to cultural homogeneity in Japan, and, in part, on the lack of recognition of people as independent persons, then a greater variety of values espoused by the public and the more urgent need to communicate with the rest of the world should naturally cause greater value to be attached to speech. And herein lies the essential reason for a greater interest in oral communication in recent years and for some optimism about the future of the interpreting profession in this country.

Notes

1. Soejima, Tahahiko (1984) : "Noryoku kaihatsu notameno eigo akusesu" ("Access to English to Develop Your Abilities"), Extra Issue of Hon'yaku no Sekai, n 3, p. 115. ("Hon'yaku no Sekai" literally means "the world of translation".)

2. Some seem to be of the view that such xenophobia is of rather recent origin, perhaps dating from the Meiji era, and is possibly deliberately fostered. But the issue probably is not merely that of xenophobia. Even if this were the case, the relevant question would be why such an attempt was so successful.

3. For interesting details, see Akira Yanabu (1976): Honyaku towa nanika - nihongo to honyaku bunka (What is Translation? - Japanese and Translation Culture), Tokyo, Hosei University Press ; and (1983) : Honyaku gakumon hihan (Critique of Translation Academia), Tokyo, Nihon Honyaku Yosei Center. Those few who really delved deeply into the matter of East and West often went through agonizing and sometimes literally maddening spiritual crises.

4. For details, see Edward T. Hall (1976) : Beyond Culture, New York, Anchor Press/Doubleday, esp. Ch. 6 \& 7.

5. Tokihiro Higuchi \& Tamotsu Nakamura (1978) : "Gengo to bunka" ("Language and Culture", in Harumi Tanaka, Ed., Gengogaku no susume (Introduction to Linguistics), Tokyo, Taishukan, pp. 210-216. Features of English-language cultures in this context are assumed to apply to a number of other European cultures as well.

6. Yasunari Kawabata (1954) : Shin bunsho tokuhon (New Reader in the Ways of Writing), Tokyo, Shinchosha, p. 33.

7. Shunsuke Tsurumi (1982) : Senjiki nihon no seishinshi : 1931-1945 (Spiritual History of Japan during the War: 1931-1945), Tokyo, Shoten, pp. 1-2. The book is the translation of the transcript delivered in a Canadian university.

8. Another important component in this sequence is the paucity of research on speaking skills in Japanese as well as on spoken Japanese by Japanese linguists. A brief review of the situation by Masao Hirai, attached to a now classic book on speech skills by Haruhiko Kindaiichi, makes this point very clear. See Masao Hirai : "Kaisetsu" ("Expository Comment"), to Haruhiko Kindaiichi : Hanashikotoba no gijutsu (Skills in Spoken Language), first published in 1956, paperback edition, 1977. Tokyo, Kodansha, pp. 309-318. Some of Mitsuko Saito's works on communication are important in this context. While modern linguistics in the West was able to break away from philology by shifting its emphasis from the written to the spoken 
language, Japanese linguists have perhaps faced a dual task. First the validity of that shift must be assessed Japanese, a shift that would be far more complex than for Indo-European languages. And, if the answer seems affirmative, then the change must actually be effected, overcoming many obstacles which are formidable, to say the least.

9. The universalist tendency of Seleskovitch's interpreting theory has been fine-tuned recently, and adapted to the interpreting in or out of Japanese, specially by Dr. Daniel Gile. His papers point to important aspects of our practice which we as native Japanese speakers often take for granted but which can be of immense value in improving our skills and in training aspirants.

10. It may be useful to point out the following in order to prevent a possible misunderstanding : I do not mean to say that the Japanese culture is particularly unique in the world. It is surely unique, but so are all other cultures. Every culture is unique by definition.

11. "Vox populy, vox Dei", The Asahi Shinbun, 28 October, 1985. 